\title{
Patrimonio, museos y antropología en el estado de Santa Catarina (Brasil)
}

\author{
Agustí Andreu Tomàs \\ agusti.andreu@urv.cat \\ Departamento de Antropología, Filosofía y Trabajo Social \\ Universitat Rovira i Virgili
}

Santa Catarina es un estado del sur de la República Federal de Brasil que, según datos del IBGE (Instituto Brasileño de Geografía y Estadística), alcanzaba en 2010 los 6.249.682 millones de habitantes, con un total de 293 municipios.

En 1991, el gobierno del estado creó el Sistema Estadual de Museus de Santa Caterina (Decreto n. ${ }^{\circ} 615$, de 10 de septiembre). Este sistema de museos, concebido como una red de adscripción voluntaria, reúne actualmente alrededor de 170 museos (públicos y privados) de 86 municipios diferentes. La tipología de los museos de Santa Catarina presenta, como no podía ser de otra manera, una gran variabilidad de patrimonios y de denominaciones: museos históricos, de arte, ecomuseos, casas museo, museos de música, museos al aire libre, museos municipales, casas de memoria, museos comunitarios, museos universitarios... De esta somera lista nos interesa comentar brevemente una serie de denominaciones que no tienen demasiada presencia en Europa. Nos referimos, principalmente, a los museos comunitarios y a las casas de memoria.

Los museos comunitarios, de larga tradición en América Latina, son numerosos en el sur del Brasil; es el caso del Museu Comunitário Engenho do Sertao (Bombinhas) o del Museu Comunitário de Ipumirim (Ipumirim). Aún menos conocida en el ámbito europeo es la casa de memoria, institución que centra su atención en la cultura inmaterial, básicamente en la historia oral y los documentos sonoros y gráficos, y que, en el estado de Santa Catarina, recibe diferentes denominaciones (centro, estación, casa, espacio, etc.): Centro de Memórias Antonio Zanuzzo (Seara), Espaço de Memória de Araquari (Araquari), Estaçao da Memoria (Joinville) o Casa da Memória. Fundaçao Flanklin Cascaes (Florianópolis).

La mayoría de los museos del estado se encuentra todavía en una de las primeras fases por las que pasó la institución museística, la fase del coleccio- 
nismo, que implica, por un lado, la existencia de museos de tipo tradicional, en el sentido de que el museo es un edificio que alberga unas colecciones y que es visitado por un público (museo = edificio + colección + público) y, por otro, la inexistencia de patrimonializaciones in situ, pues más allá de las cuatro paredes del museo esta institución no desarrolla ninguna actividad. Veamos seguidamente un ejemplo ilustrativo.

En el interior del estado se desarrolló, a principios del siglo xx, la Guerra del Contestado, un conflicto armado de tipo mesiánico originado por una disputa de límites territoriales entre los estados de Santa Catarina y Paraná. En realidad, el problema de los límites territoriales fue el catalizador del descontento existente en la zona a causa de las desigualdades sociales y económicas, que se vieron agravadas por la construcción del ferrocarril por la compañía de origen americano Southern Brazil Lumber \& Colonization Company y la cesión, por parte del gobierno del Brasil, de la propiedad de los 15 kilómetros de tierra a lado y lado de la vía del tren. El descontento de los habitantes de la zona dio paso, con la intervención de diversos monjes, a una revuelta armada que se inició en 1912 y finalizó en 1916 con la victoria de las tropas gubernamentales. En el actual valle del Contestado y en otras zonas más próximas al estado de Paraná encontramos una serie de museos que guardan testimonios de esa guerra (armas, fotografías y documentos); sin embargo, ninguno de ellos incluye en su gestión los vestigios que sobre el territorio existen de la mencionada guerra: grutas donde vivían los monjes, fuentes de agua santa, cruces de cedro plantadas por los monjes, trincheras, escenarios de las batallas... El patrimonio se circunscribe, por tanto, a las colecciones que posee el museo y deja de lado los elementos del territorio. Obviamente existen excepciones, como por ejemplo las patrimonializaciones in situ del Ecomuseu Ribeirao da Ilha (Florianópolis) o del Ecomuseu Dr. Agobar Fagundes (Blumenau).

Otro aspecto interesante de los museos de Brasil lo encontramos en la existencia de museos universitarios, algo poco frecuente en nuestro país. Según nuestros datos, en Santa Catarina existen seis museos universitarios: Museu da Universidade do Extremo Sul Caterinense (UNESC), Museu Universitario Prof. Osvaldo Rodriguez Cabral de la Universidade Federal de Santa Catarina (UFSC), Museu Universitario Willer Zumblick de la Universidade do Sul de Santa Catarina (UNISUL), Ecomuseu Univali de la Universidade do Vale de Itajaí (UNIVALI), Museu Ao Ar Livre do princesa Isabel de la Universidade 
Barriga Verde (UNIBAVE) y el Museu Dr. Fritz Müller de la Fundaçao Universidade Regional de Blumenau (FURB). De estos museos, uno de ellos es de ecología (FURB) y otro de arqueología (UNISUL); los cuatro restantes, si bien abordan la temática del patrimonio etnológico, muestran realidades muy distintas. El museo de la UNESC es un centro de memoria con un peso importante del patrimonio etnológico, pero, según sus responsables, el fondo de antropología ya no existe y el museo no es visitable. El ecomuseo UNIVALI es un museo de fósiles de dinosaurios cuyos restos no son de Brasil; no se trata pues de un ecomuseo, sino de un museo situado en una isla donde se desarrolla un proyecto de turismo sostenible. De los cuatro museos universitarios de temática etnológica únicamente quedan dos que funcionan, más o menos, de la manera como se espera que funcione un museo; se trata de los museos de la UNIVABE y la UFSC. La opinión que nos hemos formado acerca de estos dos últimos museos, a partir de los datos recogidos, es que se trata de instituciones que funcionan un poco al margen del marco de la antropología académica y estarían más próximos al mundo del folklore.

Lo apuntado sobre estas líneas nos permite entender por qué la mayor parte del trabajo sobre patrimonio de los diferentes profesores universitarios de antropología se orienta fuera de la institución museística y se articula en torno a tres claros ejes: el patrimonio urbano, la identidad y el turismo. Precisamente las autoras de los tres artículos que siguen a estas notas representan la vanguardia de la relación entre antropología y patrimonio en el estado de Santa Catarina en cada uno de esos tres ejes.

La profesora Alicia de Castells, que, por su formación en arquitectura, se ha dedicado mayoritariamente a los estudios sobre rehabilitación de barrios urbanos y al análisis de la relación entre patrimonio y cultura en América Latina, nos ofrece un artículo de corte teórico sobre las rehabilitaciones urbanas. La autora se interroga en él sobre los efectos de la homogeneización de las rehabilitaciones del tejido urbano, las racionalidades simbólicas y de representación de los espacios urbanos y las nuevas formas de apropiación de la ciudad, que pasan por el descubrimiento de su arcaísmo y autenticidad, y sobre las dinámicas inherentes a los patrimonios urbanos y su función de dinamización social y económica en la ciudad contemporánea.

La profesora Margarita Barretto, especialista en turismo en toda el área de América Latina y que actualmente está llevando a cabo un proyecto de investi- 
gación sobre la gestión de los espacios turísticos catalogados como Patrimonio de la Humanidad en la zona de las misiones entre Brasil y Argentina, nos presenta un trabajo sobre el patrimonio urbano y la percepción de los diferentes actores sociales sobre el proceso de revitalización de una calle del casco antiguo de Florianópolis. La autora nos explica cómo el crecimiento de la ciudad contemporánea ha implicado que el espacio urbano haya dejado de ser público y, en cierta manera, se haya destinado para el uso de un determinado grupo social. En la actualidad, muchos de los procesos de rehabilitación pretenden precisamente devolver al espacio urbano ese carácter público que han perdido. En este sentido, el artículo nos relata la evaluación de los resultados de esa rehabilitación a través de las percepciones de los distintos grupos sociales implicados en la apropiación de ese espacio urbano.

Finalmente, la profesora Adiles Savoldi, especialista en el estudio de la relación entre etnicidad, identidad y patrimonio, nos presenta un artículo que, en el fondo, plantea la problemática y las estrategias inherentes a los procesos de recuperación de las identidades indias. En su trabajo se presentan las diferentes formas como, en este caso los grupos Kaingang, organizan y construyen las fronteras de la diferencia, desde un punto de vista interno (se rememora el pasado para pensar la diferencia que hay que destacar en el presente) y externo (el turismo étnico permite intercambios culturales que sirven asimismo para pensar la identidad y resignificar los valores). 